\title{
Analysis of Signaling Events by Dynamic PhosphoFlow Cytometry
}

Guylène Firaguay ${ }^{1,2,3}$ and Jacques $A$. Nunès ${ }^{1,2,3} *$

${ }^{1}$ Institut National de la Santé et de la Recherche Médicale, Unité 891, Centre de

Recherche en Cancérologie de Marseille, F-13009, Marseille, France ; ${ }^{2}$ Institut PaoliCalmettes, F-13009 Marseille, France ; ${ }^{3}$ Université de la Méditerranée, F-13007, Marseille, France.

*Corresponding author: E-mail, jacques.nunes@inserm.fr

INTRODUCTION

MATERIALS

EQUIPMENT

Cell Culture and Staining

Flow Cytometry and Data Analysis

\section{RECIPES}

INSTRUCTIONS

Cell Preparation

Pretreatment of Cells with Inhibitors

Intracellular phospho-protein staining

Staining for surface markers

Flow cytometry analysis

RELATED TECHNIQUES

NOTES AND REMARKS

REFERENCES AND NOTES 


\begin{abstract}
Many proteins involved in cell signaling are phosphorylated. To determine the phosphorylation status of these signaling molecules at the single-cell level, we present a protocol for using state-specific antibodies to detect target phosphoproteins with fluorescence measurements by flow cytometry. To improve the signal intensity, a sandwich-labeling method for the analysis of signaling proteins is performed. By comparing the phosphorylation state of proteins in the presence and absence of sodium pervandate, a nonspecific protein tyrosine phosphatase inhibitor, we determined the relative amount of tyrosine phosphorylated protein in the samples, which reflects the activity of the signaling pathway. This dynamic approach in combination with the signal amplification through a sandwich-labeling method, increased the accuracy and reproducibility of the measurements compared to a single analysis avoiding internal controls defining the maximum level of phosphorylation.
\end{abstract}

\title{
INTRODUCTION
}

Intracellular phosphorylated proteins (phosphoproteins) are actors in cellular processes, spanning from signal transduction to cell metabolism, cell cycle control, development, and differentiation. The activity of many signaling proteins is regulated by phosphorylation of serine, threonine, or tyrosine residues, or some combination thereof. These phosphorylation changes are posttranslational events that are controlled by the combined action of two opposing enzymes, protein phosphatases and kinases (1).

The clinical importance of protein phosphorylation is underlined by the fact that several protein kinases have been implicated in cancer as oncogenes, and this activity is antagonized by phosphatases, functioning as tumor suppressors (2). One example is the phosphatidylinositol 3-kinase (PI3K) to Akt axis a signaling pathway that is controlled by phosphorylation-dephosphorylation mechanisms and appears to be altered in several diseases, including cancer (3). Tumor cells and immortalized cell lines typically present aberrant activation signaling events compared to those in samples from healthy animals or patients (4).

Gene expression and protein abundance profiling experiments do not necessarily assess protein activity $(5,6)$. For proteins with functions that are controlled by phosphorylation, the experimental determination of residues that can be phosphorylated, as well as their phosphorylation state are important (1). For proteins that are activated by specific phosphorylation events, measuring the phosphorylation state of the protein is a reliable indicator of activity. Thus, the determination of activation status of intracellular signaling phosphoproteins provides additional layers of information compared with information obtained through transcriptional and protein profiling studies. Methods that facilitate assessment of phosphoprotein status not only contribute to our understanding of cell signaling mechanisms, but may also have roles in the development and implementation of personalized cancer therapies. Methods for ascertaining robust measurements of the phosphorylation state of intracellular signaling proteins in single primary tumor cells with the sensitivity, specificity, and precision are needed to provide clinically useful information.

We present a dynamic phosphoflow proteomic method that uses state-specific antibodies to detect target phosphoproteins by fluorescence-activated cell sorting (FACS). We assess the activity of the signaling pathways following exposure of the cells to either the pleiotropic chemical sodium pervanadate, which inhibits protein tyrosine phosphatases (7), or to specific kinase inhibitors. For cells exposed to 
pervanadate, proteins that are relatively unphosphorylated (inactive under basal conditions) will exhibit a large increase in the abundance of the phosphorylated form upon pervanadate treatment; whereas those proteins that are already phosphorylated (active under basal conditions) will exhibit only a limited increase in the abundance of the phosphorylated form following pervanadate treatment (Fig. 1A). For cells exposed to a specific inhibitor, phosphoflow analysis reveals whether a particular signaling pathway is already activated or not (Fig. 1B).

In addition, this method can be used to screen new compounds and identify signaling targets in drug discovery. To illustrate both the use of pervanadate and a specific inhibitor, we describe the application of either pervanadate or wortmannin, an antifungal antibiotic that inactivates PI3K (8) to the human monocytic cell line U937 (cells with a PTEN mutation) or the human erythromyeloblastoid leukemia cell line K562 (cells with the Bcr-Abl translocation).

To amplify the signal, we apply a sandwich-labeling method, which involves the application of a biotin-conjugated secondary antibody followed by detection with a fluorescently conjugated streptavidin (Fig. 2).

We demonstrate the application of this method by analyzing the activity of the PI3KAkt pathway by measuring the phosphorylation of Akt at $\mathrm{Ser}^{473}$ and then extend the analysis to other signaling pathways defined by phosphorylation of other signaling components. As with the other methods described above, this Protocol relies on the availability of phosphorylation state-specific antibodies that recognize the target protein.

The technique has the potential to allow the identification of the signaling state of cells from patients, thus facilitating the transformation of the concept of personalized therapy into a clinical reality.

\section{MATERIALS}

Biotin-SP-AffiniPure F(ab')2 Frag Donkey Anti-Rabbit IgG $(H+L)$, (\# 711-066-152, Jackson ImmunoResearch product, Beckman Coulter) secondary antibodies

Note: Secondary antibody can be any biotin-conjugated antibody against the immunoglobulin class and species of phosphorylation state-specific antibodies.

CD3-PE-Cy5 mouse anti-human CD3 monoclonal antibody (\# 555334, BD

Biosciences Pharmingen)

CD13-FITC mouse anti-human CD13 monoclonal antibody (\# IM0778U, IOTest ${ }^{\circledR}$ Beckman Coulter)

Note: For detection of cell surface markers, the antibodies must be directly conjugated to the appropriate fluorophore.

Fetal calf serum (FCS) (\# CVFSV F00-01, Eurobio)

Fixation and permeabilization solution (Cytofix/Cytoperm) (\# 554714, BD Biosciences)

Note: This solution contains formaldehyde, a suspected carcinogen. Avoid contact with skin, eyes, and mucous membranes and avoid breathing fumes. It can be harmful if inhaled, or by contact with skin, or if swallowed. In case of contact with eyes, rinse immediately with plenty of water and seek medical advice. Use only in well-ventilated areas. 
Flow cytometer calibration beads [Sphero ${ }^{\mathrm{TM}}$ Rainbow calibration particles (6 peaks), 6.0-6.4 $\mu \mathrm{m}$, (\# 556288, BD Biosciences)]

Isotype control antibody for CD3-PE-Cy5 (\# 555750, BD Biosciences Pharmingen)

Isotype control antibody for CD13-FITC (\# A07795, IOTest ${ }^{\circledR}$ Beckman Coulter)

Note: Directly conjugated isotype controls (irrelevant antibodies of the same immunoglobulin class and species as the relevant surface marker antibodies) are required negative controls.

Isotype control antibody for phosphorylated $\mathrm{Akt}\left(\mathrm{Ser}^{473}\right)$ and phosphorylated CrkL $\left(\mathrm{Tyr}^{207}\right.$ ) antibodies (\# I 8140, SIGMA)

Note: Unconjugated isotypic controls (irrelevant antibodies of the same immunoglobulin class and species as the relevant phosphorylation statespecific antibodies) are required negative controls.

Hydrogen peroxide $\left(\mathrm{H}_{2} \mathrm{O}_{2}\right) 30 \%$ (\# 23619.264, NORMAPUR Prolabo)

Permeabilization and wash buffer (Perm/Wash Buffer) 10×, (\# 554723, BD

Biosciences)

Phosphate-buffered saline (PBS) 10×, (\# 70013065, GIBCO)

Rabbit monoclonal antibody that recognizes phosphorylated Akt $\left(\mathrm{Ser}^{473}\right.$ ) (clone 193H12, (\# 4058, Cell Signaling Technology)

Rabbit monoclonal antibody that recognizes phosphorylated CrkL $\left(\mathrm{Tyr}^{207}\right.$ ) (\# 3181, Cell Signaling Technology) XXX primary antibodies

Note: For detection of the phosphorylated proteins, primary antibodies can be any unconjugated purified phosphorylation state-specific antibodies that recognize the phosphoprotein target in flow cytometry experiments.

Roswell Park Memorial Institute (RPMI) 1640 media (\# Z1875, GIBCO)

Sodium orthovanadate, crystalline powder, ( \#S6508, SIGMA)

Note:This compound is toxic [Chemistry Abstracts Service (CAS) number, 13721-39-6].

Streptavidin conjugated with phycoerythrin (Streptavidin-PE), (\# IM3325, Beckman Coulter)

Wortmannin (\# 681675, Calbiochem)

\section{EQUIPMENT}

\section{Cell culture and staining}

Standard equipment for cell culture risk group level 2 (RGL-2): laminar flow cabinet, $\mathrm{CO}_{2}$ incubator $37^{\circ} \mathrm{C}$

50 mL-flasks

12-Well plates

Pipette-Aid

Refrigerated centrifuge fitted with buckets and adapters for centrifuging $15-\mathrm{mL}$ conical centrifuge tubes and plate carrier for buckets for centrifuging 96-well plates 
Water bath $\left(37^{\circ} \mathrm{C}\right)$

Pipetman

Pipetman ultra multichannel

96-well round-bottom microtiter plates

$12 \times 75 \mathrm{~mm}, 5 \mathrm{~mL}$ polystyrene round bottom test tubes (FACS tubes)

$15 \mathrm{~mL}$ Polystyrene conical centrifuge tubes, $(15-\mathrm{mL}$ centrifuge tubes)

Vortex

Flow Cytometry and Data Analysis

FACs Can flow cytometer (BD Biosciences)

Note: The minimum requirement is a flow cytometer equipped with $488 \mathrm{~nm}$ laser.

Computer

Note: Data may be stored either locally on the computer attached to the flow cytometer or on remote analysis stations connected to a computer network that is also used to store flow cytometry data.

FlowJo (BD Biosciences) or Cell Quest (BD Biosciences)

Microsoft Excel

\section{RECIPES}

\section{Recipe 1: RPMI-1640 -10\% FCS}

Add $50 \mathrm{~mL}$ of sterile FCS to one $0.5 \mathrm{~L}$ bottle of sterile RPMI. Store at $4^{\circ} \mathrm{C}$ for up to 1 month.

\section{Recipe 2: RPMI-1640-5\% FCS}

Dilute RPMI-1640 Medium + 10\% FCS (Recipe 1) with RPMI-1640 until 5\% FCS is achieved.

\section{Recipe 3: RPMI-1640-2\% FCS}

Dilute RPMI-1640 Medium + 10\% FCS (Recipe 1) with RPMI-1640 until 2\% FCS is achieved.

\section{Recipe 4: 100 mM Sodium Orthovanadate Stock Solution}

Dissolve sodium orthovanadate to a final concentration of $100 \mathrm{mM}$ in distilled water.

Note: This may be stored for 1 year at $-20^{\circ} \mathrm{C}$.if the solution is adjusted for $\mathrm{pH}$ with $\mathrm{HCl}$, then with $\mathrm{NaOH}(9))$.

\section{Recipe 5: Pervanadate Solution (10 $\mathrm{mM})$}

$100 \mathrm{mM}$ Sodium Orthovanadate Stock Solution (Recipe 4) $20 \mu \mathrm{L}$

$30 \% \mathrm{H}_{2} \mathrm{O}_{2}$

Mix together and then add the following:

RPMI-1640 + 2\% FCS (Recipe 3) 
Mix and incubate for 15 minutes at room temperature in the dark before using.

\section{Recipe 6: Pervanadate Solution $(500 \mu \mathrm{M})$}

Dilute $50 \mu \mathrm{L} 10 \mathrm{mM}$ Pervanadate Solution (Recipe 5) into $950 \mu \mathrm{L}$ of RPMI-1640 + $2 \%$ FCS (Recipe 3).

Note: This solution must be prepared immediately before use.

\section{Recipe 7: 1 mM Wortmannin Solution}

Dissolve wortmannin to a final concentration of $1 \mathrm{mM}$ in DMSO

Note: This may be stored for up to 2 months at $-20^{\circ} \mathrm{C}$ in dark.

\section{Recipe 8: Perm/Wash Buffer}

Prepare a fresh $1 \times$ solution by diluting $10 \times$ BD Perm/Wash Buffer stock with distilled water.

\section{Recipe 9: PBS}

Prepare a solution at $1 \times$ solution by diluting $10 \times$ PBS stock solution with distilled water.

\section{Recipe 10: Primary Antibody Solutions}

Prepare a fresh solution at 1x solution by diluting 100x rabbit monoclonal antibody that recognizes phosphorylated $\mathrm{Akt}\left(\mathrm{Ser}^{473}\right)$ stock solution with 1x Perm/Wash Buffer (Recipe 8)

Prepare a fresh solution at $1 \mathrm{x}$ solution by diluting 50x rabbit monoclonal antibody that recognizes phosphorylated CrkL $\left(\mathrm{Tyr}^{207}\right.$ ) stock solution with 1x Perm/Wash Buffer (Recipe 8)

Prepare a fresh solution at $1 \mathrm{x}$ solution by diluting 48000x Isotype control antibody for phosphorylated antibodies stock solution with 1x Perm/Wash Buffer (Recipe 8)

Note: The optimal dilution for other primary antibodies must be determined empirically or, if commercially available, should be prepared and used according to the manufacturer's instructions.

\section{Recipe 11: Secondary Antibody Solution}

Prepare a fresh solution at $1 \mathrm{x}$ solution by diluting 500x Biotin-SP-AffiniPure F(ab')2 Frag Donkey Anti-Rabbit IgG stock solution with 1x Perm/Wash Buffer (Recipe 8)

Note: The optimal dilution for other secondary antibodies must be determined empirically or, if commercially available, should be prepared and used according to the manufacturer's instructions.

\section{Recipe 12: Streptavidin-PE Solution}

Prepare a fresh solution at $1 \mathrm{x}$ solution by diluting 50x Streptavidin conjugated with phycoerythrin stock solution with 1x Perm/Wash Buffer (Recipe 8)

Note: The optimal dilution for streptavindin-PE must be determined empirically or, if commercially available, should be prepared and used according to the manufacturer's instructions.

\section{Recipe 13: Directly Conjugated Antibody Solutions}

Prepare a fresh solution at $1 \mathrm{x}$ solution by diluting 50x CD3-PE-Cy5 mouse antihuman CD3 monoclonal antibody stock solution with PBS (Recipe 9) 
Prepare a fresh solution at 1x solution by diluting 50x CD13-FITC mouse anti-human CD13 monoclonal antibody stock solution with PBS (Recipe 9)

Prepare a fresh solution at $1 \mathrm{x}$ solution by diluting 50x Isotype control antibody for CD3-PE-Cy5 stock solution with PBS (Recipe 9)

Prepare a fresh solution at $1 \mathrm{x}$ solution by diluting 50x Isotype control antibody for CD13-FITC stock solution with PBS (Recipe 9)

Note: The optimal dilution for other directly conjugated antibodies must be determined empirically or, if commercially available, should be prepared and used according to the manufacturer's instructions.

\section{Recipe 14: Flow Cytometer Calibration Beads}

In a FACS tube, resuspend one drop of $(\sim 20 \mu \mathrm{L})$ flow cytometer calibration beads into $500 \mu \mathrm{L}$ of $1 \times$ PBS (Recipe 9).

\section{INSTRUCTIONS}

\section{Cell Preparation}

Cell lines or primary cells may be analyzed by dynamic phosphoflow cytometry. We provide details for the analysis of the human monocytic cell line U937 (cells with a PTEN mutation), the human erythromyeloblastoid leukemia cell line K562 (cells with the Bcr-Abl translocation), and the human T cell line HUT78.

Note: This protocol can be used with primary cells such as peripheral blood mononuclear cells (PBMCs) (from freshly isolated cells or thawed frozen samples).

For commercially available cell lines, we recommend following the supplier's instructions regarding culture medium and growth conditions, for example, any supplements to the growth medium and conditions for passaging the cells. However, it is important that the cells are suspended in a medium with a low concentration of calcium, such as RPMI medium, for analysis. Thus, cells grown in Dulbecco's modified Eagle medium (DMEM) should be transferred to RPMI-based medium when they are collected for analysis.

Ideally, negative- and positive-control cells for which the phosphorylation status of the target protein under the experimental conditions is known, as well as the test cells for which the phosphorylation status of the target protein will be determined, should be analyzed.

1. Count the cells using Trypan Blue to determine cell viability

2. Resuspend cultured cells at a final concentration of $1 \times 10^{6}$ cells $/ \mathrm{mL}$ in RPMI-10\% FCS (Recipe 1).

Note: From $3 \times 10^{6}$ cells we can analyze 5 to 10 phosphoproteins per cell type and per two conditions (UT and treated) in single staining.

Note: From $3.3 \times 10^{6}$ cells we can analyze 5 to 10 phosphoproteins per cell type and per two conditions (UT and treated) in multiparameter staining for a combinaison of 3 fluorochromes..

3. Transfer $10 \mathrm{~mL}$ of the cell suspension to a $50 \mathrm{~mL}$-size flask and incubate at $37^{\circ} \mathrm{C}$, $5 \% \mathrm{CO}_{2}$ for 24 hours. 
Note: Cultured cells should be in the logarithmic growth phase. Adherent cells should be passed 2 to 3 days prior to analysis and cells should be 70 to $85 \%$ confluent when collected for analysis.

\section{Pretreatment of Cells with Inhibitors}

Any cell-permeable kinase or phosphatase inhibitor can be used. We describe the application of pervanadate (to analyze the activity of signalling pathways involving tyrosine phosphorylation) and wortmannin (to analyze the activity of pathways downstream of PI3K).

\section{Pervanadate pretreatment}

1. Count the cells using Trypan Blue to determine cell viability.

2. Transfer cell suspension to a $15-\mathrm{mL}$ centrifuge tube.

3. Centrifuge the cell suspension at $420 \mathrm{~g}$ for $5 \mathrm{~min}$ at $4^{\circ} \mathrm{C}$.

4. Resuspend the cell pellet at a final concentration of $1 \times 10^{6}$ cells $/ \mathrm{mL}$ in RPMI-5\% FCS (Recipe 2).

5. Plate cell suspension in one well of a well plate.

Note: The volume depends on the number of phosphoproteins to be analyzed. For example, to analyze 5 to 10 phosphoproteins per cell type and per two conditions (UT and treated) in single staining, plate $3 \times 10^{6}$ cells $13 \mathrm{~mL}$ of cell suspension in one well of a 12-well plate. For a combinaison of 3

fluorochromes in multiparameter staining plate $3.3 \times 10^{6}$ cells $13.3 \mathrm{~mL}$ of cell suspension.

6. Incubate covered plate at $37^{\circ} \mathrm{C}$ for 1 hour.

7. Transfer cell suspensions to $15-\mathrm{mL}$ centrifuge tubes.

8. Centrifuge at $420 \mathrm{~g}$ for 5 minutes at $4^{\circ} \mathrm{C}$.

9. Place the tubes on ice.

10. Remove the supernatant with a suction system.

11. Resuspend cells in cold RPMI-2\% FCS (Recipe 3).

Note: The volume depends on the number of phosphoproteins to be analyzed. For example, to analyze 5 to 10 phosphoproteins per cell type and per two conditions (UT and treated) in single staining resuspend the $3 \times 10^{6}$ cells in $150 \mu \mathrm{L}$ of cold RPMI-2\% FCS. For a combinaison of 3 fluorochromes in multiparameter staining resuspend the $3.3 \times 10^{6}$ cells with $165 \mu \mathrm{L}$.

12. Label two FACS tubes [untreated cells (UT), pervanadate-treated cells (pV)] and place tubes on ice.

13. Transfer cell suspension to FACS (UT) and (pV) and keep on ice until ready to proceed.

Note: The volume depends on the number of phosphoproteins to be analyzed.

For example, to analyze 5 to 10 phosphoproteins per cell type and per two conditions (UT and treated) in single staining transfer $100 \mu \mathrm{L}\left(2 \times 10^{6} \mathrm{cells}\right)$ of cell suspension to FACS (UT) and $50 \mu \mathrm{L}\left(1 \times 10^{6}\right.$ cells) to FACS ( $p$ V). For a combinaison of 3 fluorochromes in multiparameter phosphoproteins transfer 
$115 \mu \mathrm{L}\left(2.3 \times 10^{6}\right.$ cells $)$ of cell suspension to FACS (UT) and $50 \mu L\left(1 \times 10^{6}\right.$ cells $)$ to $F A C S(p V)$.

14. Transfer all tubes in $37^{\circ} \mathrm{C}$ water bath and incubate 1 minute.

15. Add Pervanadate Solution $(500 \mu \mathrm{M})$ (Recipe 6) to the $\mathrm{pV}$ sample and mix well.

Note: The volume depends on the number of phosphoproteins to be analyzed. For example, to analyze 5 to 10 phosphoproteins in single staining or in multiparameter (3 fluorochromes) staining add $5 \mu \mathrm{L}$ of Pervanadate to FACS $(p V)$ in the $50 \mu L\left(1 \times 10^{6}\right.$ cells $)$ of cell suspension.

16. Add RPMI-2\% FCS (Recipe 3) to the UT samples and mix well.

Note: The volume depends on the number of phosphoproteins to be analyzed. For example, to analyze 5 to 10 phosphoproteins in single staining add $10 \mu \mathrm{L}$ of RPMI-2\% FCS to FACS (UT) and for multiparameter (3 fluorochromes) staining add $11.5 \mu \mathrm{L}$.

17. Incubate 5 minutes at $37^{\circ} \mathrm{C}$.

18. Add pre-warmed Cytofix/Cytoperm to all samples, mix, and incubate 10 minutes at $37^{\circ} \mathrm{C}$.

Note: The volume depends on the number of phosphoproteins to be analyzed. For example, to analyze 5 to 10 phosphoproteins per cell type and per two conditions (UT and treated) in single staining add $100 \mu \mathrm{L}\left(2 \times 10^{6}\right.$ cells $)$ of pre-

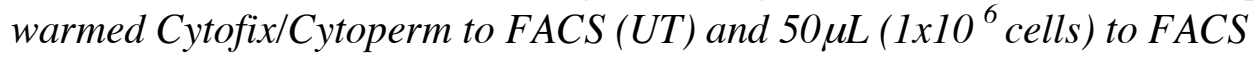
$(p V)$. For a combinaison of 3 fluorochromes in multiparameter phosphoproteins add $115 \mu \mathrm{L}\left(2.3 \times 10^{6}\right.$ cells $)$ to FACS (UT) and $50 \mu L\left(1 \times 10^{6}\right.$ cells) to FACS ( $p V)$.

19. Remove tubes from the water bath and place in a rack at room temperature (RT).

20. Add $1 \times$ Perm/Wash Buffer (Recipe 8 ) to each sample.

Note: The volume depends on the number of phosphoproteins to be analyzed. For example, to analyze 5 to 10 phosphoproteins per cell type and per two conditions (UT and treated) in single staining respectively adjust to $2 \mathrm{~mL}$ and $4 m L$ with $1 \times$ Perm/Wash Buffer to FACS (UT) and to $1 m L$ and $2 m L$ to FACS $(p V)$. For a combinaison of 3 fluorochromes in multiparameter phosphoproteins respectively adjust to $2.3 \mathrm{~mL}$ and $4.6 \mathrm{~mL}$ with $1 \times$ Perm/Wash Buffer to FACS (UT) and to $1 m L$ and $2 m L$ to FACS $(p V)$.

\section{Wortmannin pretreatment}

1. Count the cells using Trypan Blue to determine cell viability.

2. Transfer cell suspension to a $15-\mathrm{mL}$ polystyrene conical centrifuge tube.

3. Centrifuge the cell suspension at $420 \mathrm{~g}$ for $5 \mathrm{~min}$ at $4^{\circ} \mathrm{C}$.

4. Resuspend the cell pellet at a final concentration of $1 \times 10^{6}$ cells $/ \mathrm{mL}$ in RPMI-5\% FCS (Recipe 2).

5. Label two wells [untreated cells (UT), inhibitor-treated cells (Inhibitor)] of a well plate.

6. Plate cell suspension in two wells of a well plate.

Note: The volume depends on the number of phosphoproteins to be analyzed. 
For example, to analyze 5 to 10 phosphoproteins per cell type and per two conditions (UT and treated) in single staining, plate $2 \mathrm{~mL}\left(2 \times 10^{6}\right.$ cells) of cell suspension to UT well and $1 \mathrm{~mL}\left(1 \times 10^{6}\right.$ cells) to Inhibitor well . For a combinaison of 3 fluorochromes in multiparameter staining plate $2.3 \mathrm{~mL}$ $\left(2.3 \times 10^{6}\right.$ cells $)$ to UT well and $1 \mathrm{~mL}\left(1 \times 10^{6}\right.$ cells $)$ to Inhibitor well.

7. Add Wortmannin Solution (Recipe 7) to each "inhibitor" well and mix gently with a micropipette.

Note: The optimal conditions for other Inhibitors must be determined empirically or, if commercially available, should be prepared and used according to the manufacturer's instructions.

Note: The volume depends on the number of phosphoproteins to be analyzed. For example, to analyze 5 to 10 phosphoproteins in single staining or in multiparameter (3 fluorochromes) staining add $1 \mu \mathrm{L}$ of Wortmannin to Inhibitor well in the $1 \mathrm{~mL}\left(1 \times 10^{6}\right.$ cells $)$ of cell suspension .

8. Incubate covered plate at $37^{\circ} \mathrm{C}$ for 1 hour.

9. Label two 15-mL centrifuge tubes [untreated cells (UT), Inhibitor-treated cells (Inhibitor)].

10. Transfer cell suspension to $15-\mathrm{mL}$ centrifuge tubes.

11. Centrifuge at $420 \mathrm{~g}$ for 5 minutes at $4^{\circ} \mathrm{C}$.

12. Place the tubes on ice.

13. Remove the supernatant with a suction system.

14. Resuspend cells in cold RPMI-2\% FCS (Recipe 3).

Note: The volume depends on the number of phosphoproteins to be analyzed. For example, to analyze 5 to 10 phosphoproteins per cell type and per two conditions (UT and treated) in single staining resuspend cells in $100 \mu \mathrm{L}$ for UT and in $50 \mu \mathrm{L}$ for Inhibitor-treated cells of cold RPMI-2\% FCS. For a combinaison of 3 fluorochromes in multiparameter staining resuspend cells cells in $115 \mu \mathrm{L}$ for UT and in $50 \mu \mathrm{L}$ for Inhibitor-treated cells.

15. Label two FACS tubes [untreated cells (UT), inhibitor-treated cells (Inhibitor)] and place tubes on ice.

16. Transfer the appropriate cell suspensions to the FACS tubes (UT) and (Inhibitor) and place in a $37^{\circ} \mathrm{C}$ water bath. .

Note: The volume depends on the number of phosphoproteins to be analyzed. For example, to analyze 5 to 10 phosphoproteins per cell type and per two conditions (UT and treated) in single staining transfer the $100 \mu \mathrm{L}$ of cell suspension to FACS (UT) and the $50 \mu L$ to FACS Inhibitor. For a combinaison of 3 fluorochromes in multiparameter staining transfer the 115 $\mu L$ for UT and the $50 \mu \mathrm{L}$ to FACS (Inhibitor).

17. Incubate for $6 \mathrm{~min}$ at $37^{\circ} \mathrm{C}$.

18. Add pre-warmed Cytofix/Cytoperm to all samples, mix well, and incubate 10 minutes at $37^{\circ} \mathrm{C}$.

Note: The volume depends on the number of phosphoproteins to be analyzed. For example, to analyze 5 to 10 phosphoproteins per cell type and per two conditions (UT and treated) in single staining add $100 \mu \mathrm{L}\left(2 \times 10^{6}\right.$ cells) of pre- 
warmed Cytofix/Cytoperm to FACS (UT) and 50 $\mu \mathrm{L}\left(1 \times 10^{6}\right.$ cells) to FACS (Inhibitor). For a combinaison of 3 fluorochromes in multiparameter phosphoproteins add $115 \mu \mathrm{L}\left(2.3 \times 10^{6}\right.$ cells $)$ to FACS (UT) and $50 \mu L\left(1 \times 10^{6}\right.$ cells) to FACS (Inhibitor).

19. Remove tubes from the water bath and place in a rack at room temperature (RT).

20. Add $1 \times$ Perm/Wash Buffer to each sample.

Note: The volume depends on the number of phosphoproteins to be analyzed. For example, to analyze 5 to 10 phosphoproteins per cell type and per two conditions (UT and treated) in single staining respectively adjust to $2 m L$ and $4 m L$ with $1 \times$ Perm/Wash Buffer to FACS (UT) and to $1 m L$ and $2 m L$ to FACS (Inhibitor). For a combinaison of 3 fluorochromes in multiparameter phosphoproteins respectively adjust to $2.3 \mathrm{~mL}$ and $4.6 \mathrm{~mL}$ with $1 \times \mathrm{Perm} / \mathrm{Wash}$ Buffer to FACS (UT) and to $1 m L$ and $2 m L$ to FACS (Inhibitor).

\section{Antibody Staining}

Samples may be permeabilized, fixed, and analyzed following intracellular staining of the target phosphoprotein(s) or the samples may be additionally labelled with antibodies that recognize cell surface markers. This latter staining process is optional, but does allow the cells to be sorted by surface markers.

Cytofix/Cytoperm and Perm/Wash Buffer contain the detergent saponin. Because saponin-mediated cell permeabilization is a reversible process, it is important to keep the cells in the presence of saponin during both the staining and washing steps.

Staining is performed in 96 -well round bottom microtiter plates. To minimize cross-contamination during staining, we recommend that sample-filled wells be surrounded by empty wells on all sides. Negative-and positive-control cells should also be included. To analyze one phosphoprotein per cell type and per inhibitor in a single stain, 3 wells will be prepared (Fig. 3A):

- UT sample plus the isotype control antibody

- UT sample plus the antibody against the target phosphoprotein

- Inhibitor-treated sample ( $\mathrm{pV}$ or Inhibitor) plus the antibody against the target phosphoprotein

To perform labelling of the intracellular phosphoprotein and cell surface markers, then a combination of fluorochromes with nonoverlapping spectra may be used. PE is always used to detect the intracellular phosphoprotein. For example, a combination of 3 fluorochromes may be used and monitored in different channels of the flow cytometer (represented as FLn, where $\mathrm{n}$ is the channel number): fluorescein isothiocyanate (FITC) in FL1, PE in FL2, and PE-Cy5 in FL3. We have used a FITC-labeled antibody that recognizes the myeloid surface antigen CD13 and a PE-Cy5-labeled antibody that recognizes the $\mathrm{T}$ cell surface antigen CD3. To perform this type of multiparameter analysis and to analyze one phosphoprotein per cell type and per inhibitor 6 wells will be prepared (Fig. 3B):

- UT sample plus the isotype control antibody for the FITC-, PE-Cy5surface directly conjugated antibodies and for PE- intracellular antibody 
- UT sample plus the FITC-, PE-Cy5- directly conjugated antibodies against the target surface markers and PE- intracellular antibody against the target phosphoprotein

- Inhibitor-treated sample (pV or Inhibitor) plus the FITC-, PE-Cy5directly conjugated antibodies against the target surface markers and PE- intracellular antibody against the target phosphoprotein

- UT sample plus FITC- directly conjugated antibody against the target surface marker only (for compensation)

- UT sample plus PE-Cy5- directly conjugated antibody against the target surface marker only (for compensation)

- UT sample plus PE- antibody against the target phosphoprotein only (for compensation)

\section{Intracellular phosphoprotein staining}

1. Prepare 96-well round-bottom microtiter plates labelled such that the samples will be surrounded by empty wells.

2. Vortex cell suspensions and plate $200 \mu \mathrm{L}$ of cell suspension per well in a 96-well round-bottom microtiter plate.

Note:Depending on the volume of PermWash buffer (Inhibitor pre-treatment steps\# 20), the cell number is the 96-well plates will be $2 \times 10^{5}$ cells/well from cell suspension at $1 \times 10^{6} \mathrm{cell} / \mathrm{mL}$ or $1 \times 10^{5} \mathrm{cells} /$ well from cell suspension at $0.5 \times 10^{6} \mathrm{cell} / \mathrm{mL}$

3. Centrifuge at RT at $670 \mathrm{~g}$ for $3 \mathrm{~min}$.

4. Quickly flick into sink and immediately invert the plate on a paper towel

5. Add $100 \mu \mathrm{L}$ of primary antibody solution [isotype control antibody (Recipe 10) or antibody against the target phosphoprotein (Recipe 10)] to the appropriate well(s) and mix by gently pipetting at least 3 times.

6. Incubate for $20 \mathrm{~min}$ at $\mathrm{RT}$.

7. Centrifuge at RT at $670 \mathrm{~g}$ for $3 \mathrm{~min}$.

8. Quickly flick into sink and immediately invert the plate on a paper towel .

9. Add $200 \mu \mathrm{L}$ of Perm/Wash Buffer per well and mix by gently pipetting at least 3 times.

10. Centrifuge at RT at $670 \mathrm{~g}$ for $3 \mathrm{~min}$.

11. Quickly flick into sink and immediately invert the plate on a paper towel .

12. Add $100 \mu \mathrm{L}$ of biotin-conjugated secondary antibody solution (Recipe 11) per well and mix by gently pipetting at least 3 times.

13. Incubate for $20 \mathrm{~min}$ at $\mathrm{RT}$.

14. Centrifuge at RT at $670 \mathrm{~g}$ for $3 \mathrm{~min}$.

15. Quickly flick into sink and immediately invert the plate on a paper towel .

16. Add $200 \mu \mathrm{L}$ of Perm/Wash Buffer per well and mix by gently pipetting at least 3 times.

17. Centrifuge at RT at $670 \mathrm{~g}$ for $3 \mathrm{~min}$. 
18. Quickly flick into sink and immediately invert the plate on a paper towel.

19. Add $100 \mu \mathrm{L}$ of Streptavidin-PE Solution (Recipe 12) per well and mix by gently pipetting at least 3 times.

20. Incubate for $15 \mathrm{~min}$ at $\mathrm{RT}$ in the dark.

21. Add $150 \mu \mathrm{L}$ of Perm/Wash Buffer per well and mix by gently pipetting at least 3 times.

22. Centrifuge at RT at $670 \mathrm{~g}$ for $3 \mathrm{~min}$.

23. Quickly flick into sink and immediately invert the plate on a paper towel.

24. Add $200 \mu \mathrm{L}$ of Perm/Wash Buffer per well and mix by gently pipetting at least 3 times.

25. Centrifuge at RT at $670 g$ for $3 \mathrm{~min}$.

26. Quickly flick into sink and immediately invert the plate on a paper towel.

Note: If staining for surface markers, then proceed to next section "Staining for Surface Markers". If not proceed to step 27.

27. Resuspend the cell pellet in $200 \mu \mathrm{L}$ of $1 \times$ PBS (Recipe 9).

28. Transfer the cell suspension from wells to FACS tubes.

Note: The samples can be stored at $4{ }^{\circ} \mathrm{C}$ in the dark for 24 hours until flow cytometry acquisition.

\section{Staining for surface markers}

One fundamental application flow cytometry is the discrimination of cell types based on the differential abundance or presence of surface proteins. Cells may be stained for intracellular phosphorylated proteins and stained for surface markers, allowing differences in signalling responses in mixed populations of cells to be resolved.

Before choosing to label for surface markers, it should be noted that many cell surface markers are sensitive to fixation and permeabilization procedures and will not be recognized by the relevant antibodies afterward such procedures. Thus, we recommend that surface marker labelling under the conditions required for intracellular labelling be tested prior to performing this type of analysis.

In order to perform multiparameter analysis of intracellular and surface proteins, the cell surface antigen must be recognized with antibodies that are directly conjugated to a fluorochrome. The fluorochromes should have minimal spectral overlap. Additional controls are also required compared to the detection of only the intracellular phosphoprotein. The additional controls are necessary for correctly setting compensation parameters, especially if a spectral overlap exists. Single-labeled and multi-labeled controls are needed to ensure correct parameters. They are set to optimize cell number and minimize detector overlap.

1. To the appropriate wells $100 \mu \mathrm{L}$ of directly conjugated antibody solution (Recipe 13) per well and mix by gently pipetting at least 3 times.

Note: This step follows step 26 in the preceding section.

2. Incubate for $15 \mathrm{~min}$ at RT in the dark.

3. Add $150 \mu \mathrm{L}$ of PBS (Recipe 9) per well and mix by gently pipetting at least 3 times. 
4. Centrifuge at RT at $670 \mathrm{~g}$ for $3 \mathrm{~min}$.

5. Quickly flick into sink and immediately invert the plate on a paper towel.

6. Add $200 \mu \mathrm{L}$ of PBS (Recipe 9) per well and mix by gently pipetting at least 3 times.

7. Centrifuge at RT at $670 \mathrm{~g}$ for $3 \mathrm{~min}$.

8. Quickly flick into sink and immediately invert the plate on a paper towel.

9. Resuspend the cell pellet in $200 \mu \mathrm{L}$ of PBS (Recipe 9) and transfer the cell suspension from wells to FACS tubes.

Note: The samples can be stored at $4{ }^{\circ} \mathrm{C}$ in the dark for 24 hours until flow cytometry acquisition.

\section{Flow Cytometry Analysis}

This procedure is based on the use of a FACs Can flow cytometer, but can be adapted to similar equipment. This procedure requires prior familiarity with flow cytometry techniques and instrumentation.

\section{Flow cytometer setup}

1. Turn on the flow cytometer and computer and wait at least 15 min for the lasers to warm up.

2. Remove samples from the fridge, if necessary, and keep samples in the dark at RT.

3. Launch the acquisition software by choosing 'Open

Detectors/Amps/Threshold/Compensation' from the cytometer menu and open a folder to store the files.

4. Place a FACS tube containing $500 \mu$ L Flow Cytometer Calibration Beads (Recipe 9) and acquire about 2,500 events corresponding to single beads in a forward-by-side scatter/side scatter FCS/SSC dot plot using FL2 settings suitable for human test cells (as indicated by FACS supplier's information).

Note: Beads should be mixed well prior to use.

\section{Data acquisition by flow cytometry}

Data acquisition parameters depend on if the samples were stained for a single phosphorylated protein or if multiparameter staining was performed. For single staining experiments, a dot plot showing forward-by-side scatter /side scatter (FSC/SSC) is constructed to bring cells on scale, a gate is set around the cell population of interest (possibly all cells), and a histogram showing FL2, the PE channel, is generated to display only events in the defined gate (Fig. 4).

For multiparameter staining, additional set up is required. In addition to a dot plot showing FSC/SSC for bringing the cells on scale and setting the gates around the cell population of interest (possibly all cells) (Fig. 5A), a second a dot plot is constructed from the intensity of the staining of the two surface markers. This second dot plot is used to discriminate the different cell types based on the differential expression of surface proteins (Fig. 5B). Gates are set to identify the population(s) of interest, and then a histogram is constructed showing FL2 to display only events within the corresponding gate (Fig. 5 C,D,E). A compensation procedure is also necessary. The procedure below assumes that FITC is detected in FL1, PE in FL2, and Cy5 in FL3 and that cells labelled with only a single fluorochrome, such as FITC, PE, or Cy5, are at least as bright, and preferably brighter, than the brightest test samples expected. 
Note: You cannot correctly set up compensation with dimly stained cells.

1. Construct the appropriate data acquisition settings file to run samples or open the data acquisition settings file if available.

2. Set the FCS/SSC amplifier to linear mode and FL1, FL2, and FL3 amplifiers to logarithmic mode.

Note: For single stain set FCS/SSC amplifier to linear mode and FL2amplifier to logarithmic mode

3. Place a FACS tube containing UT sample plus the isotype control antibody for the FITC-, PE-Cy5- surface directly conjugated antibodies and for PE- intracellular antibody

Note: For single stain place a FACS tube containing UT sample plus the I sotype control antibody

Note: Mix cells on a vortex at mediums speed and then introduce samples into the flow cytometer.

4. Start data acquisition in setup mode.

5. If necessary, adjust the FSC and SSC detectors to place the cell populations on the dot plot by first adjusting the voltage settings on the FSC and SSC detectors and then adjusting the threshold to remove "debris" and noncellular elements.

Note: This is done from the flow cytometer menu for the acquisition of cells.

5. Draw a gate around the cell population of interest (possibly all cells).

6. Refer to the FL2 versus FL1 plot and adjust the voltage on the FL1 detector to position the negative cell population in the first decade of the log scale median fluorescence intensity (MFI) of FL1, then adjust the voltage on the FL2 detector to position the negative cell population in the first decade of the log scale MFI FL2.

7. Refer to FL3 versus FL2 plot and adjust the voltage on the FL3 detector to position the negative cell population in the first decade of log scale MFI FL3.

Note: For single stain refer to the histogram showing FL2 to display only events in the gate and adjust the voltage on the FL2 detector to position the negative cell population in the first decade of the log scale MFI of FL2.

8. Place a FACS tube containing UT sample plus FITC- directly conjugated antibody against the target surface marker only (for compensation)

Note: Mix cells on a vortex at mediums speed and then introduce samples into the flow cytometer.

9. Refer to the FL2 versus FL1 plot and adjust the FL2-\%FL1 compensation control to bring the FITC-only cell population to the point that the FL2 median of this population is approximately the same as the FL2 median of the negative cells.

Note: This is typically moving the cells downward on the plot.

10. Place a FACS tube containing UT sample plus PE-Cy5- directly conjugated antibody against the target surface marker only (for compensation)

Note: Mix cells on a vortex at mediums speed and then introduce samples into the flow cytometer

11. Refer to the FL3 versus FL2 plot and adjust the FL2 - \%FL3 compensation control to bring the PE-Cy5-only cell population to the point that the FL2 median of this 
population is approximately the same as the FL2 median of the negative cells.

Note: This is typically moving the cells leftward on the plot.

12. Place a FACS tube containing UT sample plus PE- antibody against the target phosphoprotein only (for compensation)

Note: Mix cells on a vortex at mediums speed and then introduce samples into the flow cytometer

13. Refer to the FL2 versus FL1 plot and adjust the FL1 - \%FL2 compensation control to bring the PE-only cell population to the point that the FL1 median of this population is approximately the same as the FL1 median of the negative cells.

Note: This is typically moving the cells leftward on the plot.

14. Refer to the FL3 versus FL2 plot and adjust the FL3 - \%FL2 compensation control to bring the PE-only labeled cell population to the point that the FL3 median of this population is approximately the same as the FL3 median of the negative cells.

Note: This is typically moving the cells downward on the plot.

Note: Steps 8 through 14 represent the compensation procedure. If the voltage is changed on any of the three detectors after this is done, then the compensation procedure must be repeated.

Note: Steps 8 through 14 are the compensation procedure and only apply to multiparameter experiments. For single staining experiments, proceed to steps 1 through 7.

12. Start data acquisition in acquire mode and acquire data for a minimum of 2,500 gated events of a minority cell population of interest.

13. Adjust the gate around the cell population of interest (possibly all cells) if necessary.

14. Clean the machine with bleach and water, leave it on standby or shut down.

Note: Data analysis can be performed any time after acquisition has been finished.

\section{Dynamic phosphoflow data analysis}

1. From the flow cytometry data analysis software program, create a window with dot plots and histograms (see Fig. 4 and 5 for example) and then open the file to be analyzed.

Note: Once the process has been done once a template can be created for dynamic phosphoflow analysis and used instead of creating a window with the plots and histograms each time.

2. Drag the gates over the correct populations. For single stain, drag the gate over the population in the FSC/SSC dot plot. Set a gate around each population in which you are interested (possibly all cells) and a histogram showing FL2 to display only events in the defined gate (Fig. 4).

For multicolor stain, drag the gates over the correct populations in the dot plot in which you are interested and histograms showing FL2 to display only events in the above gates (Fig. 5).

3. Check if all FL2 histograms are compatible with single populations of cells, if needed (with a small number of cells and/or noise events) adjust gates or place 
markers around the peaks.

Note: It is normal practice to set a gate on displays of fluorescent parameters using a region around a selected population defined on a FSC/SSC plot. However, occasionally, it is unclear as to where the region should be drawn. In such cases, a back gating is performed. For this draw a region on a fluorescence parameter, which defines the population of interest, and the region used to set a gate on FCS/SSC plot. The scatter can now be seen more clearly so that the correct region can be set, in turn, to use as a gate in the normal manner.

4. Select all plots and histograms and copy them to a Microsoft Word document.

5. From the CellQuest or FlowJo document, transfer MFI values corresponding to phosphorylation of the signaling protein for each tested condition (UT, $\mathrm{pV}$, Inhibitor), cell types, and phosphoproteins analyzed to a Microsoft Excel file for calculations.

6. Calculate, in Microsoft Excel, for cell types and phosphoproteins analyzed, relative phosphorylation. For pervanadate-treated samples, calculate this as

Relative phosphorylation $=$ MFI UT $/$ MFI pV

For kinase inhibitor-treated samples, calculate this as

Inhibition $(\%)=[1-($ MFI Inhibitor/MFI UT) $] \times 100$

7. Construct, in Microsoft Excel, a graph corresponding to relative phosphorylation or to inhibition in function of cell types and phosphoproteins analyzed (see Fig. 6A and B for examples).

\section{RELATED TECHNIQUES}

Several methods are available for measuring the phosphorylation analysis (phosphoproteomics) of signaling proteins. Conventional methods, such as immunoprecipitation followed by immunoblotting or immunofluorescence microscopy with antibodies that specifically recognize phosphorylated proteins, have provided a wealth of information about cell signaling, but generally permit the analysis of a few signaling molecules per experiment. Futhermore, these methods have several important limitations (1). The stoichiometry of phosphorylation is usually very low , where all the cells from a cell population are not responding at the same time and/or relative few proteins in the total are phosphorylated. Some signaling molecules are present at low abundance within cells (10)and phosphorylated proteins may be underdetected unless protein phosphatase activity is adequately inhibited during preparation and purification steps of cell lysates. Moreover, these methods are laborious, time consuming, and difficult to adapt for high-throughput analysis (11).

Mass spectrometry methods overcome many of the limitations of the conventional biochemical techniques (12-14). These methods are very powerful to analyze signaling events in large scale into a cell population. However, cells may develop individual flux of signaling events that is buried in the lump of data generated at the cell population level.

Detecting signaling at the single cell level is a critical challenge to probe single cell responses (15). By using a microfluidics device combined with immunocytochemistry, microfluidics techniques allows analysis based on phosphorylation-specific antibodies and can be applied to single-cell analysis (16). However, this method has been reported only for adherent-cell signaling experiments. 
Phospho-flow proteomics are methods that combine phosphorylation-specific antibodies with flow cytometry. One approach employs flow cytometry to analyze cell or tissue lysates with a cytometric bead array (17). Garry Nolan's group at Stanford University (http://proteomics.stanford.edu/nolan/) has developed phospho-flow proteomic methods that allow analysis of phosphoproteins in single cells (18)Cite Krutzik et al. Nat. Chem. Biol. 2008 or some other primary literature here ). With this approach one can correlate intracellular signaling events with discrete subpopulations of cells.

Signaling events are dynamic and phosphorylation sites exist at very low stoichiometric levels (19). Further confounding analysis, is that, in most cases, phosphorylation is a transient and a reversible event (11). The consideration of signaling networks as dynamic systems is crucial and requires methods applicable for the analysis of individual living cells (20).

One way to discern signaling networks that are unique to cancer cells is to expose the cancer cells to potentiating inputs, rather than relying upon the basal amounts of protein phosphorylation alone (21). Lymphocyte subsets from normal donors exhibit little donor-to-donor variation in cytokine-induced phosphoprotein responses (21). In contrast, the responses of cells from acute myeloid leukemia (AML) patients varied in numerous ways from one patient to another and were different from normal donors. Our method does not rely on cytokine stimulation and thus should avoid the issues related to donor variability. Just as single-cell phosphoflow proteomics have been used for drug screening by measuring the phosphorylation state of endogenous proteins following exposure to cytokines (18), our dynamic phosphoflow analysis can also be applied to drug discovery.

\section{NOTES AND REMARKS}

We present three examples that illustrate the application of the dynamic phosphoflow method. We performed phosphoflow analysis to determine whether a signaling pathway is constitutively activated (signaling "on") or not (signaling "off") by analyzing the serine phosphorylation of Akt at the position $473\left(\mathrm{Ser}^{473}\right)$ and tyrosine phosphorylation of CrkL at the position $207\left(\mathrm{Tyr}^{207}\right)$ in the T cell line HUT78 that has functional PTEN (phosphatase and tensin homolog) $(4,22)$ ) and the U937 myeloid cell line that is deficient in PTEN $(4,22)$ (Fig. 4). Cells deficient in PTEN exhibit basal activation of the PI3K/ Akt pathway (3). These two cell lines serve ascontrol cells: HUT78 cells should be phosphoAkt negative (PI3K/Akt signaling should be relatively low, "off") and U937 cells should be phosphoAkt positive (PI3K/Akt signaling high, "on").

To show that this method can reveal information about cells for which the state of the signaling pathway is unknown, we compared the results obtained with the U937 and HUT78 cells with those obtained with the chronic myeloid leukaemia (CML) cell line K562 that is PTEN positive, but for which the status of basal phosphorylation of Akt on $\mathrm{Ser}^{473}$ is controversial $(22,23)$. The Akt phosphorylation profile of K562 was similar to the PTEN-deficient cell line, U937 (grey histograms). Moreover, when K562 or U937 cells were treated with pervanadate, the increase in Akt phosphorylation was low, consistent with this pathway active under basal conditions (red curves, Fig. 4B). Relative phosphorylation, which corresponds to phosphorylation quantitation changes in response to pervanadate, was calculated for the HUT78, U937, and K562 cells. A positive threshold was defined as 0.3 , which was based on the mean + 2 standard deviations of relative phosphorylation of the HUT78 cells (Fig. 6A). Thus, the pathway was considered "on" if the relative phosphorylation values 
exceeded 0.3. Indeed, the relative phosphorylation values of the U937 and K562 cells were 0.7 and 0.5 , respectively, thus, the "test" cells (K562 cells) exhibit basal activity of the PI3K pathway.

The K562 cells also serve as a positive control for analysis of the activity of the oncoprotein tyrosine kinase BCR-ABL, which is present in K562 cells (24), but not in U937 or HUT78 cells. We assayed the phosphorylation status of the adaptor protein CrkL, which is phosphorylated by BCR-ABL, in these three cell lines and, as expected, high basal phosphorylation of CrkL was only detectable in K562 cells (Fig. 4B) and the increase of phosphorylation with pervanadate is low (Fig. 4B, red curve versus grey histogram). Thus the relative CrkL phosphorylation in K562 cells (calculated as MFI UT/ MFI pV is high (Fig. 6A).

We also illustrated how with the combination of intracellular phosphorylation-state labeling and extracellular surface marker labeling can differentiate the activity of a signaling pathway in a population of mixed cells. We performed multiparameter labeling by combining direct extracellular staining with intracellular phosphoprotein staining of a mixed cell population containing 20\% HUT78 T cells (Akt signaling off, CD3 positive) and 80\% U937 myeloid cells (Akt signaling on, CD13 positive) (Fig.

5). Cells were treated or not with different agents (wortmannin and pervanadate) and then fixed and permeabilized, stained with antibody against phosphoAkt $\left(\mathrm{Ser}^{473}\right)$ detected by the sandwich method, and stained with a mixture of antibodies against CD3 (conjugated to PE-Cy5) and CD13 (conjugated to FITC). By selecting all living cells (Fig. 5A), the HUT78 cells are difficult to detect (Fig. 5C). However, by selecting independently the two cell types based on their surface markers, CD3 or CD13 (Fig. 5B), the cell-specific status of the phosphorylation of Akt Ser ${ }^{473}$ becomes resolvable (Fig. 5D-E). Moreover, treatment of the cells with the PI3K inhibitor (wortmannin) does not change the Akt $\mathrm{Ser}^{473}$ phosphorylation status in HUT78 cells (Fig. 5E, blue curve versus grey histogram), but substantially decreases the basal Akt $\mathrm{Ser}^{473}$ phosphorylation state in U937 cells (Fig. 5D, blue curve versus grey histogram).

To demonstrate the potential usefulness in drug development and assessment of the specificity of inhibitor activity, we examined the effects of wortmannin on the phosphorylation of the BCR-ABL target CrkL, which is not known as downstream of PI3K. The high phosphorylation of Akt in U937 and K562 cells was largely decreased (Fig. 7, upper histograms) by wortmannin; however, wortmannin failed to decrease the phosphorylation CrkL in K562 cells (Fig.7, lower histograms), showing that WMN doesn't affect the Bcr-Abl tyrosine kinase activity in K562 cells. Phosphorylation inhibition was quantified (Fig. 6B). A positive threshold was defined from on the basis of the HUT78 cells as $51 \%$, which is consistent with previously considered threshold (25). The percent inhibition in the U937 and K562 cells exceeded this threshold at $76 \%$ and $77 \%$, respectively. Thus, both the pervanadate data and the wortmannin data suggest that Akt is basally active in these cells and the wortmannin data further suggest that PI3K is implicated in the phosphorylation of Akt Ser ${ }^{473}$.

These examples illustrate the potential utility of this protocol to investigate the basal activaty of signaling pathways at the single-cell level, to develop kinase- or phosphatase-targeted drugs, and elucidate potential new targets of existing drugs. This dynamic approach by modulation positive and negative of kinases and phosphatases that are involved in signaling cascades, in combination with the signal amplification through a sandwich labeling method, increases the accuracy and reproducibility of the measurements compared to a single analysis without treatment with pleitropic activators of signaling pathways. 
Fig. 1. Example of how phosphorylation status can be assessed with pervanadate or specific kinase inhibitors by dynamic phosphoflow cytometry. (A) Example of how the basal activity of a kinase affects the change in a target protein's phosphorylation induced by pervanadate. (B) Example of how the basal activity of a kinase affects the change in a target protein's phosphorylation state in the presence of a specific kinase inhibitor.

Fig. 2. Diagram of the sandwich method for amplifying antibody labelling signals.

Fig. 3. Schematic representation of phosphoprotein staining in a 96-well plate.

Staining is performed in 96-well round bottom microtiter plates. These schemes are drawn for the analysis of one phosphoprotein (A) in a single intracellular labelling (targeting phosphoprotein) or (B) in a double intracellular and cell surface staining (targeting surface markers and phosphoprotein).

Plate A : position A-1 = untreated (UT) sample plus isotype control, position $\mathrm{C}-1=$ UT sample plus phosphoprotein staining, position E-1 = inhibitor (pervanadate or wortmannin)-treated sample, plus phosphoprotein staining.

Plate B : position A-1 = UT sample plus isotype controls, position C-1 = UT sample plus phosphoprotein and cell surface markers staining, position E-1 = inhibitor-treated sample, plus phosphoprotein and cell surface markers staining. Several staining controls are added with UT sample for setting compensation: position B-3 = FITConly (first cell surface marker staining alone), position B-5 = PE-Cy5 only (second cell surface marker staining alone), position B-7 = PE-only (phosphoprotein staining alone).

Fig. 4 Example of dynamic phosphoflow cytometry to determine in the phosphorylation state of a single protein. The activity of PTEN (an inhibitor of the PI3K pathway) and Bcr-Abl (kinase that phosphorylates CrkL) in the various cell lines is indicated. The phosphorylation state of Akt $\left(\mathrm{Ser}^{473}\right)$ and $\mathrm{CrkL}\left(\mathrm{Tyr}^{207}\right)$ was measured by phosphoflow analysis. (A) Intact cells were gated on scatter properties. (B) Each histogram shows the staining of untreated sample (UT) as the grey histogram and the sample treated with pervanadate $(\mathrm{pV})$ as a red line histogram. MFI, mean fluorescence intensity. Relative phosphorylation was quantified as ratio $\mathrm{MFI}=\mathrm{R}=$ MFI UT / MFI pV.

Fig. 5. Example of multiparameter analysis to determine phosphorylation state of Akt from a mixed cell population using cell surface marker labelling. The abundance of phosphorylated Akt at $\mathrm{Ser}^{473}$ (pAkt)in response to pervanadate and wortmannin of a mixed culture of U937 and HUT78 cells (ratio 4:1) was assayed. pAkt was detected with the phosphorylation-state specific antibody and CD3 and CD13 monoclonal antibodies were used to label T cells (HUT78) and cells of myeloid lineages (U937), respectively. MFI, mean fluorescence intensity. (A) Intact cells were gated on scatter properties. (B) Cells were gated based on the presence of CD3 and CD13. (C-E) Each histogram shows the staining of untreated sample (UT) as the grey histogram, pervanadate-treated samples $(\mathrm{pV})$ as a red line histogram, and wortmannin (WMN)treated samples as a blue line histogram. Relative phosphorylation $\mathrm{R}$ and phosphorylation inhibition I (\%) values appear in the histograms. (C) Analysis of the mixed U937 and HUT78 cell response. (D) The U937-specific cell response. (E) The HUT78-specific cell response. 
Fig. 6. Quantitation of Akt and CrkL phosphorylation in response to pervanadate treatment (A) or wortmannin treatment $(\mathbf{B})$ from independent experiments with single phosphoprotein labelling. In $\mathrm{A}$, the relative phosphorylation $\mathrm{R}$ was quantified as ratio MFI = R = MFI untreated (UT) / MFI pervanadate $\mathrm{pV}$ [ $\mathrm{n}=25$ HUT78; $\mathrm{n}=25$ U937; $\mathrm{n}=2 \mathrm{~K} 562$ ] are reported in the graph. Columns are the mean \pm SD of average $\mathrm{R}$ values. In B, phosphorylation inhibition was quantified as Inhibition $(\%)=\mathrm{I}(\%)=1-$ (MFI WMN / MFI UT). Quantitation of Akt and CrkL phosphorylation inhibition from independent experiments [ $\mathrm{n}=25$ HUT78; $\mathrm{n}=25 \mathrm{U} 937 ; \mathrm{n}=2$ K562] are reported in the graph. Columns are the mean \pm SD of average I (\%) values.

Fig. 7. Example of dynamic phosphoflow cytometric analysis of cell lines treated with the cell signalling inhibitor wortmannin (WMN), a PI3K inhibitor. The known activity of PTEN and Bcr-Abl, as well as the predicted basal phosphorylation state of Akt and CrkL are indicated. Intact cells were gated on scatter properties (not shown) and each histogram shows the staining of untreated sample (UT) as the grey histogram, WMNtreated sample as a blue line histogram. MFI, mean fluorescence intensity.

Phosphorylation inhibition was quantified as Inhibition $(\%)=\mathrm{I}(\%)=1-(\mathrm{MFI}$ WMN : MFI UT).

\section{REFERENCES AND NOTES}

1. F. Delom, E. Chevet, Phosphoprotein analysis: from proteins to proteomes. Proteome Sci 4, 15 (2006).

2. M. P. Myers, I. Pass, I. H. Batty, J. Van der Kaay, J. P. Stolarov, B. A. Hemmings, M. H. Wigler, C. P. Downes, N. K. Tonks, The lipid phosphatase activity of PTEN is critical for its tumor supressor function. Proc Natl Acad Sci U S A 95, 13513-13518 (1998).

3. M. Cully, H. You, A. J. Levine, T. W. Mak, Beyond PTEN mutations: the PI3K pathway as an integrator of multiple inputs during tumorigenesis. Nat Rev Cancer 6, 184-192 (2006).

4. R. W. Freeburn, K. L. Wright, S. J. Burgess, E. Astoul, D. A. Cantrell, S. G. Ward, Evidence that SHIP-1 contributes to phosphatidylinositol 3,4,5-trisphosphate metabolism in T lymphocytes and can regulate novel phosphoinositide 3-kinase effectors. J Immunol 169, 5441-5450 (2002).

5. M. Pallis, C. Seedhouse, M. Grundy, N. Russell, Flow cytometric measurement of phosphorylated STAT5 in AML: lack of specific association with FLT3 internal tandem duplications. Leuk Res 27, 803-805 (2003).

6. Y. P. Lim, Mining the tumor phosphoproteome for cancer markers. Clin Cancer Res 11, 3163-3169 (2005).

7. G. Huyer, S. Liu, J. Kelly, J. Moffat, P. Payette, B. Kennedy, G. Tsaprailis, M. J. Gresser, C. Ramachandran, Mechanism of inhibition of protein-tyrosine phosphatases by vanadate and pervanadate. J Biol Chem 272, 843-851 (1997).

8. M. P. Wymann, G. Bulgarelli-Leva, M. J. Zvelebil, L. Pirola, B. Vanhaesebroeck, M. D. Waterfield, G. Panayotou, Wortmannin inactivates phosphoinositide 3-kinase by covalent modification of Lys-802, a residue involved in the phosphate transfer reaction. Mol Cell Biol 16, 1722-1733 (1996).

9. T. Harder, M. Kuhn, Immunoisolation of TCR signaling complexes from Jurkat T leukemic cells. Sci STKE 2001, PL1 (2001).

10. S. Yoon, R. Seger, The extracellular signal-regulated kinase: multiple substrates regulate diverse cellular functions. Growth Factors 24, 21-44 (2006).

11. P. O. Krutzik, J. M. Irish, G. P. Nolan, O. D. Perez, Analysis of protein phosphorylation and cellular signaling events by flow cytometry: techniques and clinical applications. Clin Immunol 110, 206-221 (2004). 
12. A. Pandey, J. S. Andersen, M. Mann, Use of mass spectrometry to study signaling pathways. Sci STKE 2000, PL1 (2000).

13. H. Steen, A. Pandey, J. S. Andersen, M. Mann, Analysis of tyrosine phosphorylation sites in signaling molecules by a phosphotyrosine-specific immonium ion scanning method. Sci STKE 2002, PL16 (2002).

14. M. O. Collins, L. Yu, H. Husi, W. P. Blackstock, J. S. Choudhary, S. G. Grant, Robust enrichment of phosphorylated species in complex mixtures by sequential protein and peptide metal-affinity chromatography and analysis by tandem mass spectrometry. $S c i$ STKE 2005, pl6 (2005).

15. N. R. Gough, Detecting signaling in single cells. Sci Signal 1, ec406 (2008).

16. R. Cheong, C. J. Wang, A. Levchenko, Using a microfluidic device for high-content analysis of cell signaling. Sci Signal 2, pl2 (2009).

17. R. Varro, R. Chen, H. Sepulveda, J. Apgar, Bead-based multianalyte flow immunoassays: the cytometric bead array system. Methods Mol Biol 378, 125-152 (2007).

18. P. O. Krutzik, J. M. Crane, M. R. Clutter, G. P. Nolan, High-content single-cell drug screening with phosphospecific flow cytometry. Nat Chem Biol 4, 132-142 (2008).

19. P. R. Cutillas, A. Khwaja, M. Graupera, W. Pearce, S. Gharbi, M. Waterfield, B. Vanhaesebroeck, Ultrasensitive and absolute quantification of the phosphoinositide 3kinase/Akt signal transduction pathway by mass spectrometry. Proc Natl Acad Sci U S A 103, 8959-8964 (2006).

20. S. A. Johnson, T. Hunter, Kinomics: methods for deciphering the kinome. Nat Methods 2 , 17-25 (2005).

21. J. M. Irish, R. Hovland, P. O. Krutzik, O. D. Perez, O. Bruserud, B. T. Gjertsen, G. P. Nolan, Single cell profiling of potentiated phospho-protein networks in cancer cells. Cell 118, 217-228 (2004).

22. P. L. Dahia, R. C. Aguiar, J. Alberta, J. B. Kum, S. Caron, H. Sill, D. J. Marsh, J. Ritz, A. Freedman, C. Stiles, C. Eng, PTEN is inversely correlated with the cell survival factor $\mathrm{Akt} / \mathrm{PKB}$ and is inactivated via multiple mechanismsin haematological malignancies. Hum Mol Genet 8, 185-193 (1999).

23. R. C. Hui, A. R. Gomes, D. Constantinidou, J. R. Costa, C. T. Karadedou, S. Fernandez de Mattos, M. P. Wymann, J. J. Brosens, A. Schulze, E. W. Lam, The forkhead transcription factor FOXO3a increases phosphoinositide-3 kinase/Akt activity in drugresistant leukemic cells through induction of PIK3CA expression. Mol Cell Biol 28, 58865898 (2008).

24. A. Hamilton, L. Elrick, S. Myssina, M. Copland, H. Jorgensen, J. V. Melo, T. Holyoake, BCR-ABL activity and its response to drugs can be determined in CD34+ CML stem cells by CrkL phosphorylation status using flow cytometry. Leukemia 20, 1035-1039 (2006).

25. M. M. Hammer, N. Kotecha, J. M. Irish, G. P. Nolan, P. O. Krutzik, WebFlow: A Software Package for High-Throughput Analysis of Flow Cytometry Data. Assay Drug Dev Technol (2009).

26. This work was supported by grants from Institut National de la Santé et de la Recherche Médicale and the Institut National du Cancer (\# PL-06026). 

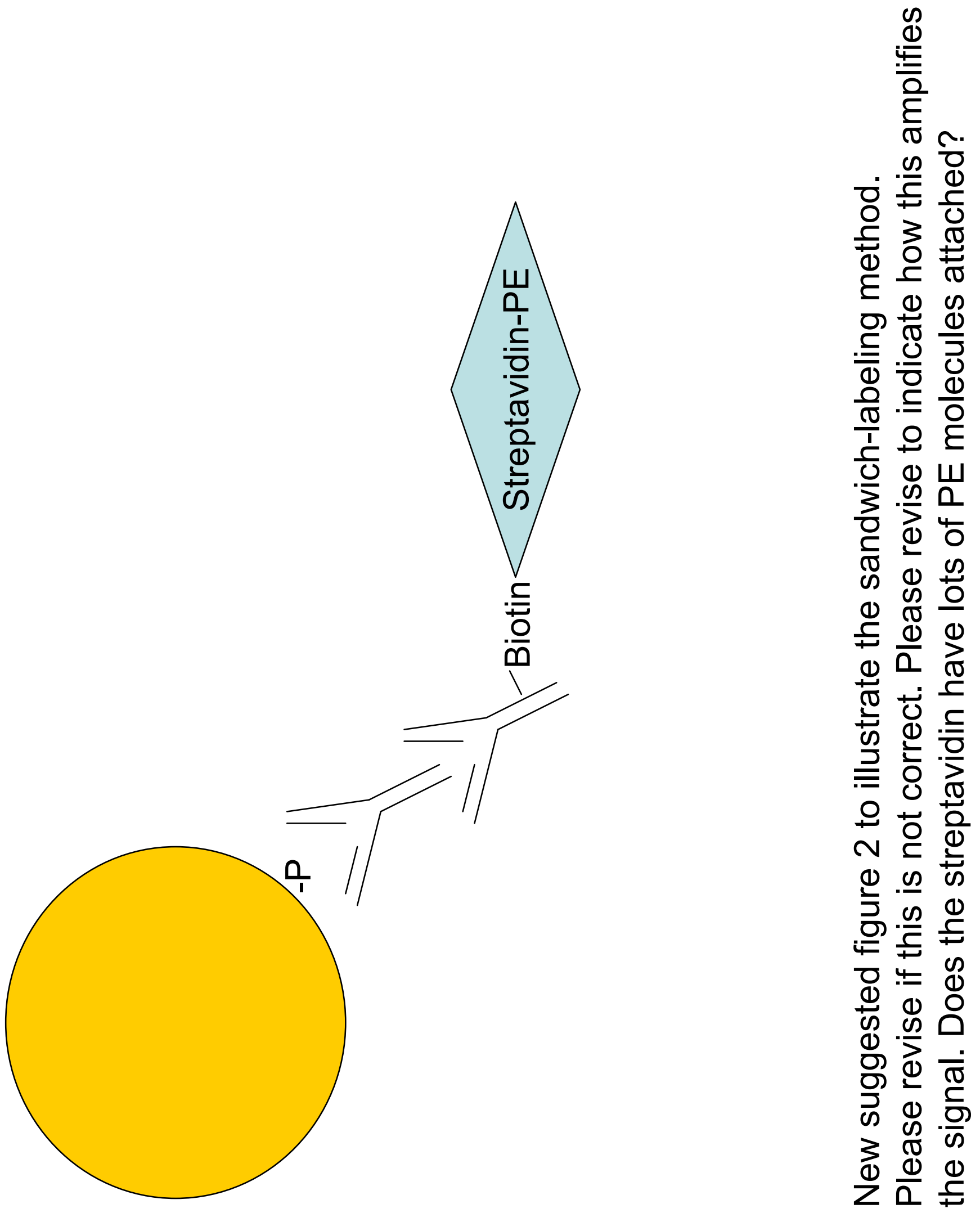


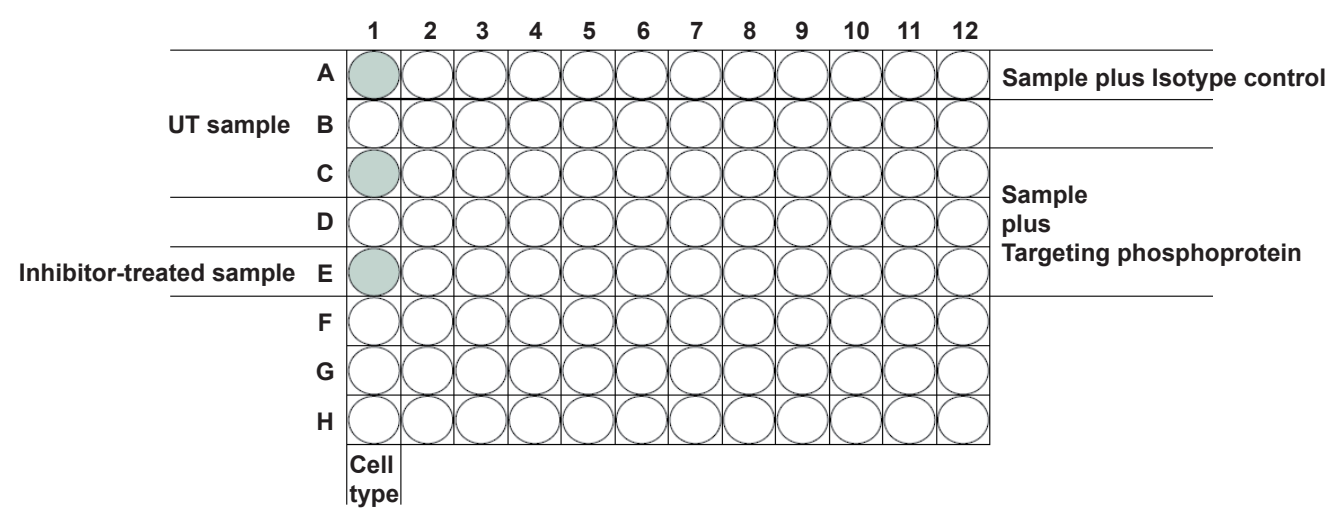

B

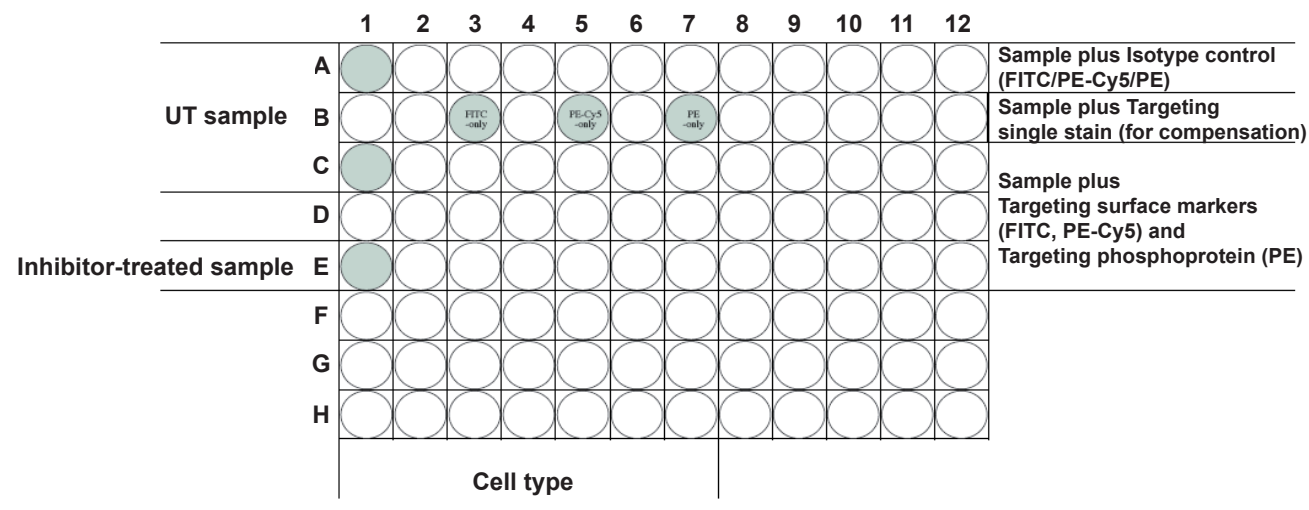


A

Control cells

Test cells

HUT78

PTEN (+) / Akt (off)

Bcr-Abl (-) / CrkL (off)

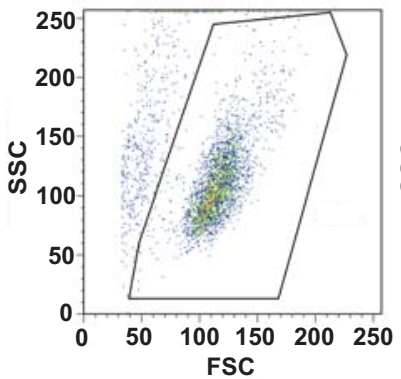

U937

PTEN (-) / Akt (on)

Bcr-Abl (-) / CrkL (off)

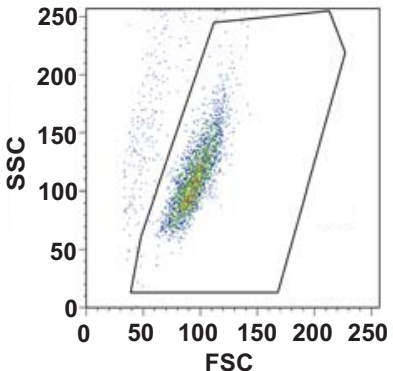

K562

PTEN (+) / Akt (?)

Bcr-Abl (+) / CrkL (on)

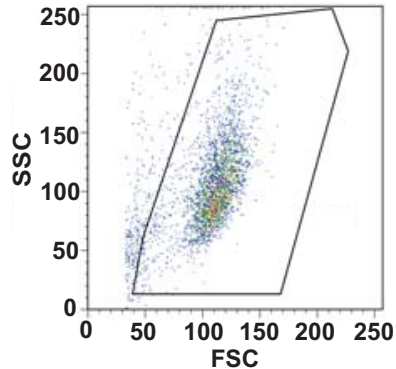

B

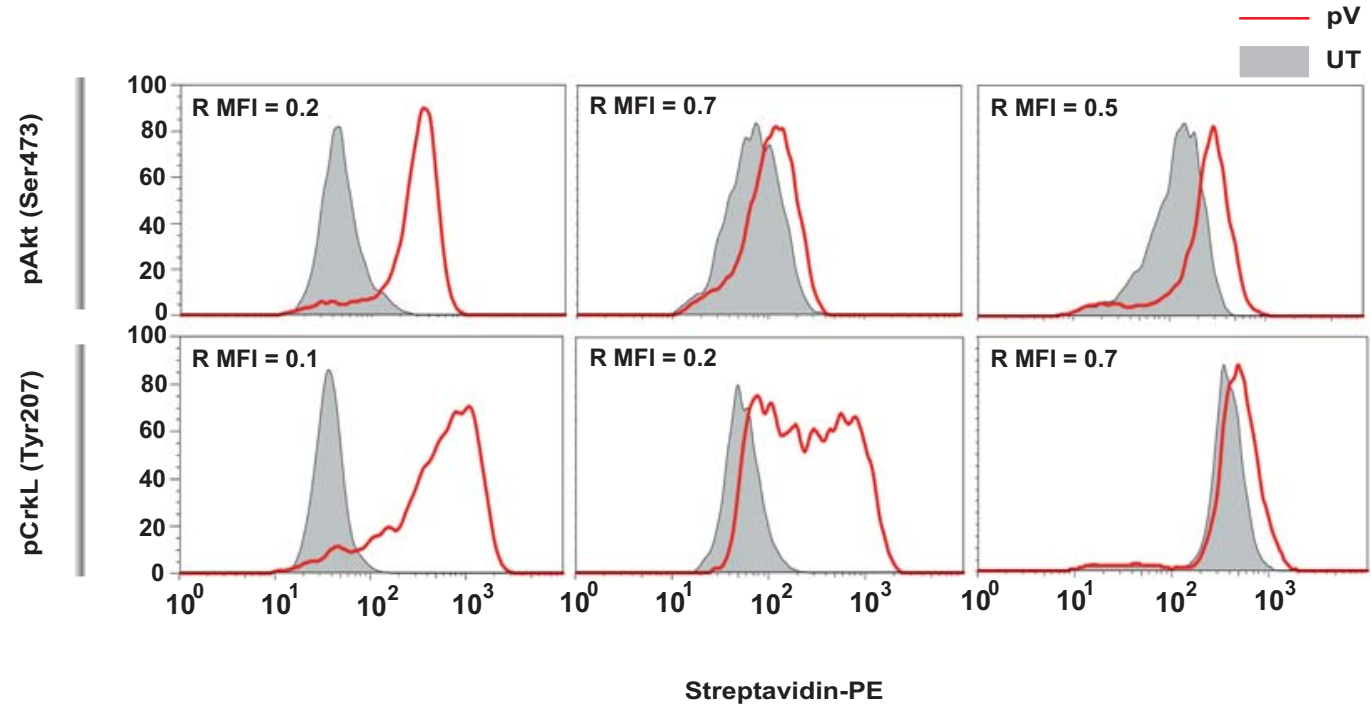


A

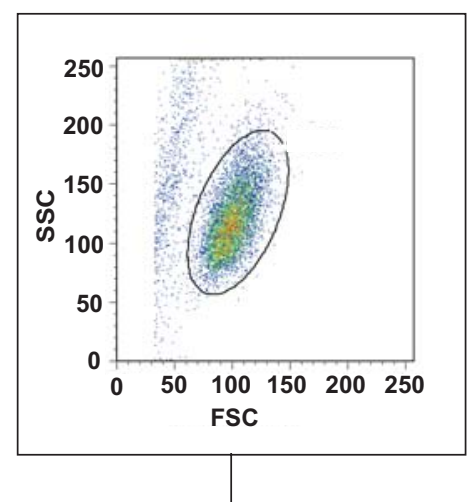

HUT78 / U937
B

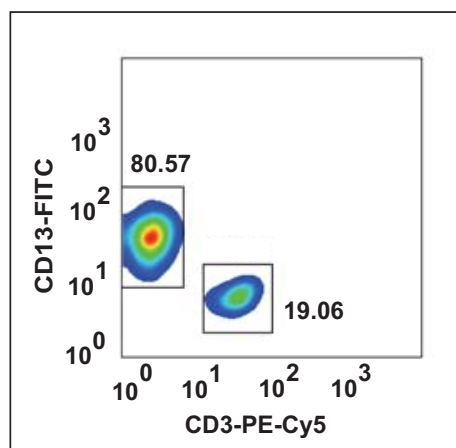

U937 CD13+

HUT78 CD3+

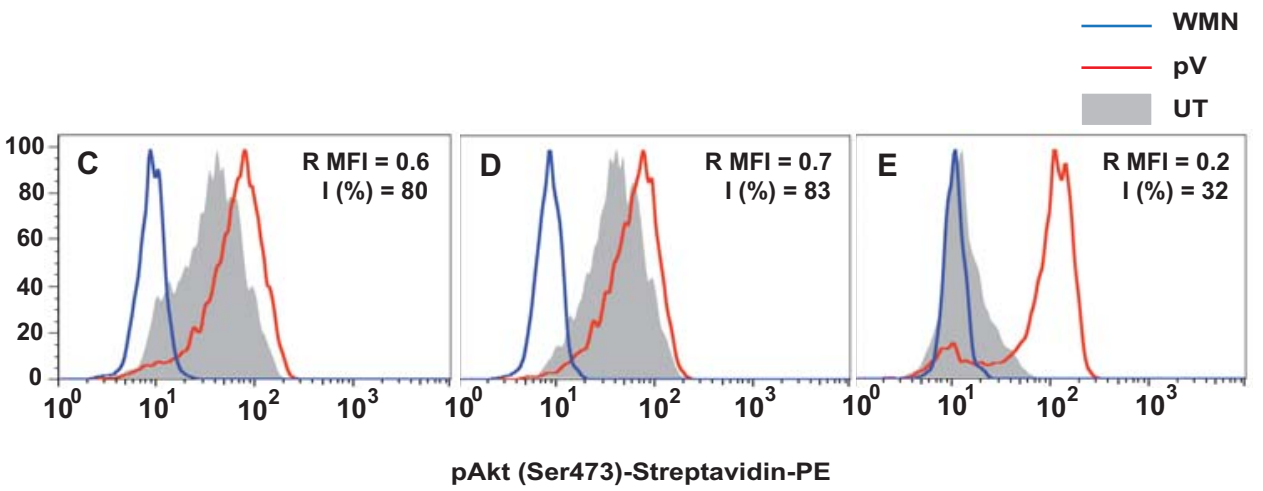


A

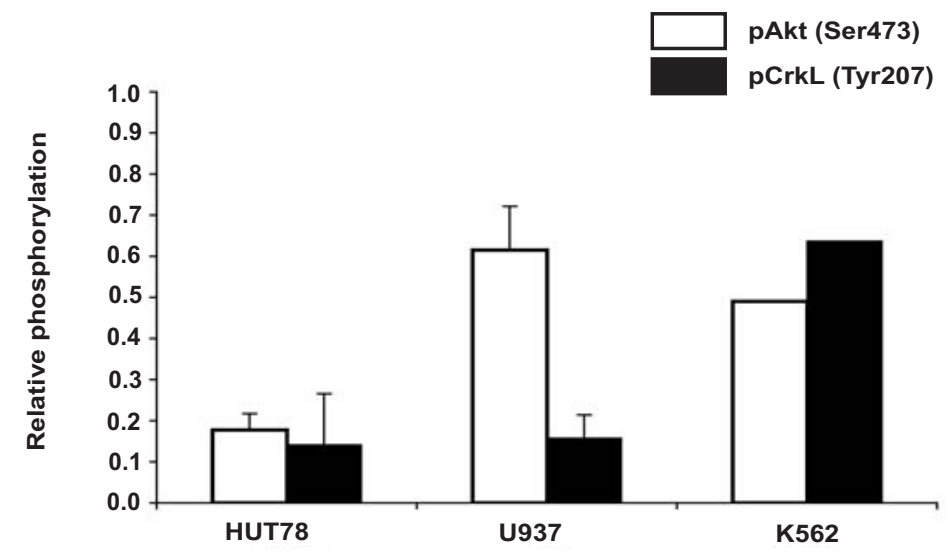

B
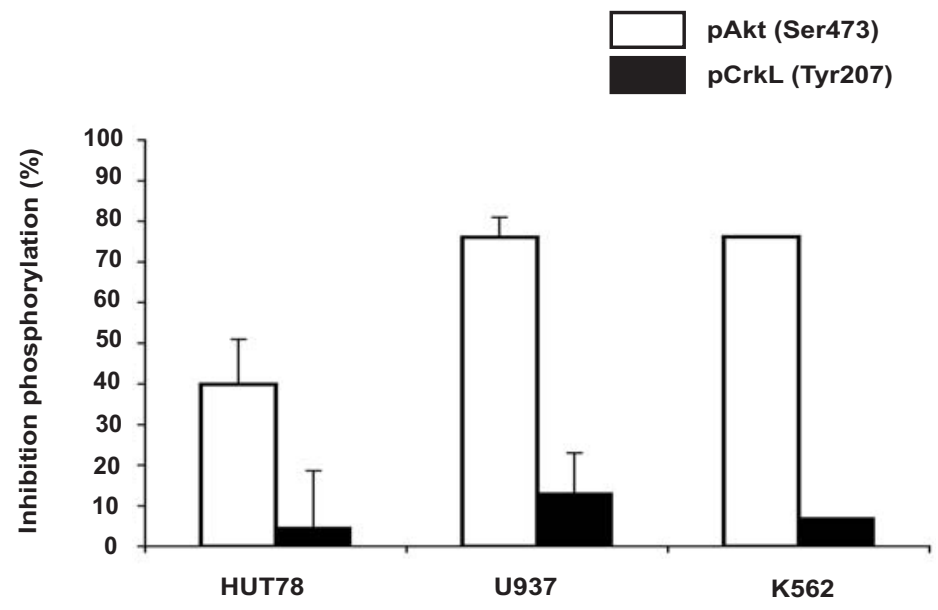


$\begin{array}{ll}\text { HUT78 } & \text { U937 } \\ \text { PTEN (+) / Akt (off) } & \text { PTEN (-) / Akt (on) } \\ \text { Bcr-Abl (-) / CrkL (off) } & \text { Bcr-Abl (-) / CrkL (off) }\end{array}$

K562

PTEN (+) / Akt (?)

Bcr-Abl (+) / CrkL (on)

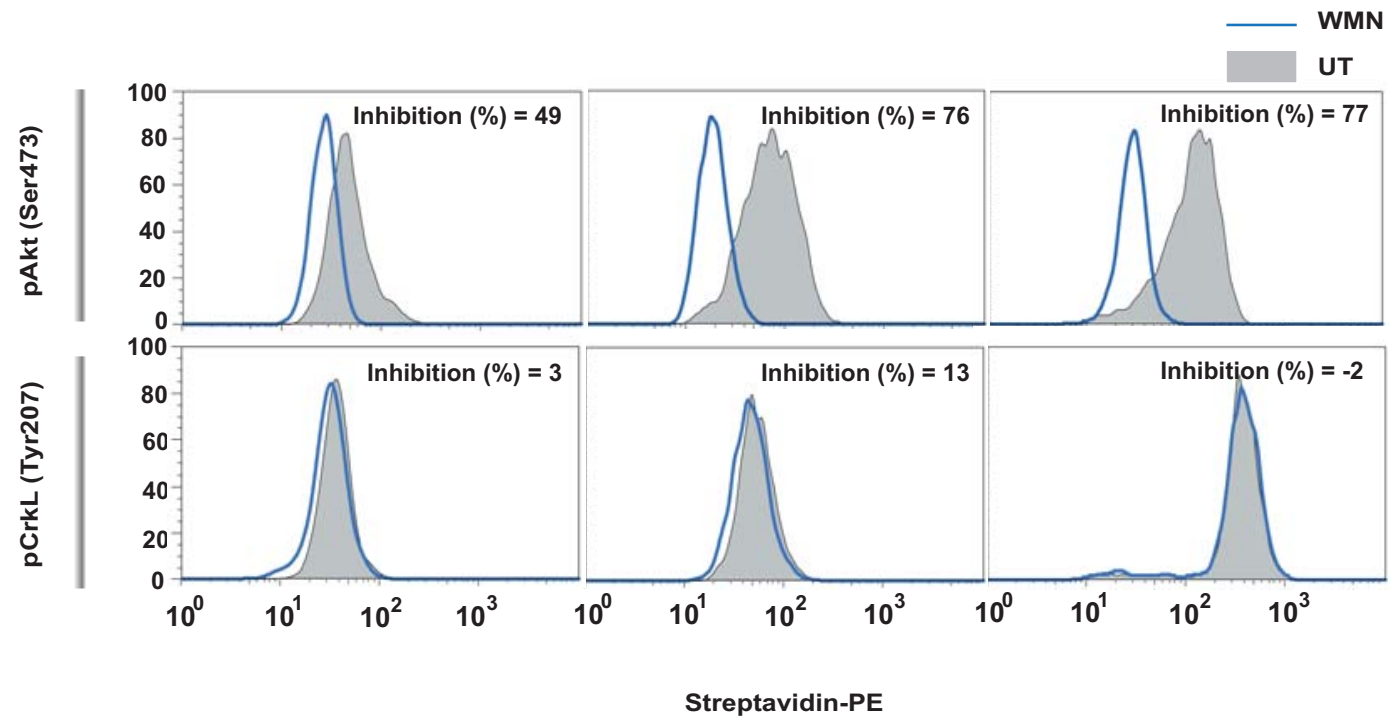

